\title{
Dual consent? Donors' and recipients' views about involvement in decision- making on the use of embryos created by gamete donation in research
}

\author{
I. Baía ${ }^{1,2+}$ (D), C. de Freitas ${ }^{1,2,3+}$ (D), C. Samorinha ${ }^{1,2}$ (D), V. Provoost ${ }^{4}$ (D) and S. Silva ${ }^{1,2^{*}}$ (D)
}

\begin{abstract}
Background: Reasonable disagreement about the role awarded to gamete donors in decision-making on the use of embryos created by gamete donation (EGDs) for research purposes emphasises the importance of considering the implementation of participatory, adaptive, and trustworthy policies and guidelines for consent procedures. However, the perspectives of gamete donors and recipients about decision-making regarding research with EGDs are still under-researched, which precludes the development of policies and guidelines informed by evidence. This study seeks to explore the views of donors and recipients about who should take part in consent processes for the use of EGDs in research.
\end{abstract}

Methods: From July 2017 to June 2018, 72 gamete donors and 175 recipients completed a self-report structured questionnaire at the Portuguese Public Bank of Gametes (response rate: 76\%). Agreement with dual consent was defined as the belief that the use of EGDs in research should be consented by both donors and recipients.

Results: The majority of participants (74.6\% of donors and $65.7 \%$ of recipients) were willing to donate embryos for research. Almost half of the donors (48.6\%) and half of the recipients (46.9\%) considered that a dual consent procedure is desirable. This view was more frequent among employed recipients (49.7\%) than among nonemployed (21.4\%). Donors were less likely to believe that only recipients should be involved in giving consent for the use of EGDs in research ( $25.0 \%$ vs. $41.7 \%$ among recipients) and were more frequently favourable to the idea of exclusive donors' consent (26.4\% vs. $11.4 \%$ among recipients).

Conclusions: Divergent views on dual consent among donors and recipients indicate the need to develop evidencebased and ethically sustainable policies and guidelines to protect well-being, autonomy and reproductive rights of both stakeholder groups. More empirical research and further theoretical normative analyses are needed to inform people-centred policy and guidelines for shared decision-making concerning the use of EGDs for research.

Keywords: Gamete donation, Embryo research, Consent forms, Stakeholder participation, Ethics, research

\footnotetext{
* Correspondence: susilva@ispup.up.pt

${ }^{\dagger}$. Baía and C. de Freitas contributed equally to this work.

${ }^{1}$ EPIUnit - Instituto de Saúde Pública, Universidade do Porto, Rua das Taipas,

no $135,4050-600$ Porto, Portugal

${ }^{2}$ Departamento de Ciências da Saúde Pública e Forenses e Educação Médica,

Faculdade de Medicina, Universidade do Porto, Porto, Portugal

Full list of author information is available at the end of the article
}

(c) The Author(s). 2019 Open Access This article is distributed under the terms of the Creative Commons Attribution 4.0 International License (http://creativecommons.org/licenses/by/4.0/), which permits unrestricted use, distribution, and

reproduction in any medium, provided you give appropriate credit to the original author(s) and the source, provide a link to the Creative Commons license, and indicate if changes were made. The Creative Commons Public Domain Dedication waiver (http://creativecommons.org/publicdomain/zero/1.0/) applies to the data made available in this article, unless otherwise stated. 


\section{Background}

Guidelines, regulations, and policies on who should be involved in giving consent for the use of embryos created by gamete donation (EGDs) in research vary substantially across countries. This is especially evident regarding the role awarded to gamete donors. The European Society of Human Reproduction and Embryology and the American National Institutes of Health acknowledge that donors relinquish all rights of ownership to the gametes from the moment embryos are created $[1,2]$. From this perspective, consent should concern only the recipients, as is currently the case in countries such as Portugal [3]. In contrast, the American Society for Reproductive Medicine and the Canadian Institutes of Health Research Guidelines are in favour of a dual consent, advising that donors should also have a say in decision-making about the use of embryos for research purposes when these embryos were created with their gametes $[4,5]$.

These heterogeneous informed consent practices on EGDs disposition are based on different meanings and interpretations attributed to traditional ethical principles and biorights [6] related to autonomy [7, 8] and ownership [7, 9]. Those who advocate for dual consent emphasize the need to acknowledge donors' views, values, and preferences and to respect their autonomy and reproductive rights, alongside those of recipients [10-12]. In fact, the literature reveals that the availability of donated gametes for reproductive purposes does not mean that their donors consent to their use in research $[2,13]$. Conversely, critical approaches that plead for consent only given by recipients encompass concerns about the protection of donors' autonomy and with a breach of altruism, which is the primary value underlying donation $[1,14]$.

Reasonable disagreement about dual consent on the use of EGDs for research purposes justifies the implementation of empirically grounded, participatory, adaptive, and trustworthy policies and guidelines for consent procedures [15]. Respect for personal autonomy, i.e. for individual's ability to make their own responsible choices knowing the available possibilities [16], is particularly difficult to translate into practice [17]. Being mindful of both donors and recipients' preferences in the consent process can help to ensure that no one is involved in an eventually undesired procedure [12, 18]. However, the perspectives of gamete donors and recipients on decision-making regarding research with EGDs are still under-researched, which precludes the development of policies and guidelines informed by evidence. This study seeks to contribute to the debate on dual consent by drawing on an empirical study carried out in Portugal, where signing of consent forms regarding embryo donation for research purposes is only asked from recipients [3]. Similar to other European countries, Portuguese gamete donation policy is undergoing change. In 2016, entitlement to fertility treatments was extended to all women aged between 18 and 49 years, independently of sexual orientation or marital status [19]. Such transitions have increased demand for donated gametes [20] and embryo disposition is likely to follow suit in the future. This research explores the views of donors and recipients about who should take part in consent processes concerned with the use of EGDs in research.

\section{Methods}

\section{Data collection and analysis}

From July 2017 to June 2018, gamete donors and recipients who attended at least one medical appointment at the Portuguese Public Bank of Gametes were invited to participate in a quantitative cross-sectional study. This Bank of Gametes is located at a public hospital which performs in vitro fertilization/intracytoplasmic sperm injection in homologous and heterologous cycles. Ethical approval was granted by the Portuguese Data Protection Authority and the Ethics Committee for Health from the hospital where data was collected. Written informed consent was obtained from all donors and recipients prior to participation in the study.

At the end of the medical appointment, donors and recipients received an informative leaflet from a health professional. Subsequently, a research team member invited them to participate in the study. Those who agreed to participate were then accompanied to a private room at the Portuguese Public Bank of Gametes where they read and signed the informed consent and completed a self-report questionnaire. Of the 329 people invited, 72 donors and 179 recipients agreed to participate in the questionnaire (response rate: $76.3 \%$ ).

The structured questionnaire was developed by the research team to assess ethical, legal and social issues involved in gamete donation, based on a review of literature and an exhaustive inventory of existing questionnaires on the subject. The questionnaire was validated by experts from the social and health sciences and by a pilot administration to donors and recipients. This process resulted in linguistic modifications and some items were removed. Following the fine-tuning, a final version of the questionnaire was devised encompassing a total of 34 questions divided into four sections: 1. Opinions about access to and governance of gamete donation (e.g. awareness of communication campaigns, views about preferred forms of payment to- and recruitment of- donors, anonymity); 2. Willingness to donate gametes to family and friends and for research purposes, as well as to receive gametes from family, friends or unknown donors; 3. Willingness to donate embryos for reproductive and research purposes, including views about who should be involved in decision-making on the use 
of EGDs in research; and 4. Sociodemographic and reproductive characteristics. A translation of the questionnaire by the authors is available as Additional file 1 .

For the purposes of this paper we only analysed results regarding the views of donors and recipients about dual consent on the use of EGDs for research purposes and their association with the following sociodemographic and reproductive characteristics: sex, age, experience with gamete donation (categorized as gamete donors and recipients), marital status (categorized as married/ living with the partner and single/divorced), working status (categorized as employed and other, including unemployed, students and retired), educational level, perceived income adequacy, previous experience on gamete donation and willingness to donate embryos for research. Educational level was assessed through a multiple-choice item with the following answer categories: 1) None, and can't read or write; 2) None, but can read and write; 3) 1st cycle of basic education (4th grade); 4) 2nd cycle of basic education (6th grade); 5) 3rd cycle of basic education (9th grade); 6) Secondary education (12th grade); 7) Bachelor's degree; 8) Licentiate degree; 9) Master's/Integrated Master's; 10) PhD. For analysis, this variable was dichotomized in $\leq$ Secondary education (12th grade) and $>$ Secondary education (12th grade). Perceived income adequacy was assessed through the question: "Thinking of your household income, would you say that your household is able to make ends meet?", being the answers recoded into a dichotomous variable: 1) insufficient, including respondents who reported subjective economic hardship (insufficient or caution with expenses); 2) sufficient, including respondents who reported that their household income is enough to make ends meet or comfortable. Participants were considered to have previous experience on gamete donation when recipients had at least one previous heterologous treatment or donors have donated gametes at least once before the current donation.

Willingness to donate embryos for research was assessed using a 5-point Likert scale ranging from "very unwilling" to "very willing" (range: 0-4). For this analysis, the answers were recoded into a dichotomous variable: "willing to donate" (answers scoring 3 or 4) or "other" (answers ranging between 0 and 2). The views of donors and recipients about dual consent were assessed by the question: "In your opinion, who should be involved in giving consent to the use of embryos created by gamete donation in research?". Response options were: gamete recipients; gamete donors; both recipients and gamete donors. These options were dichotomized as "agree" (participants who answered "both recipients and gamete donors") and "disagree" (all other participants) with dual consent. Four participants with missing values for this variable were excluded, resulting in 72 donors and 175 recipients to be included in the quantitative analysis.

\section{Statistical analysis}

Categorical variables were presented as counts and proportions, while continuous variables were summarized as medians and percentiles. Chi-square and MannWhitney tests were applied, respectively, to assess the associations and mean differences between variables. Statistical significance was set at a value of $p<0.05$. Analyses were performed using SPSS version 24.0 (Armonk, NY, USA).

\section{Results}

Most participants were female and employed, had no children and no previous experience of gamete donation, and perceived their income as sufficient (Table 1). Donors were younger, higher educated and more frequently single or divorced (Table 2). The majority of participants (74.6\% of donors and $65.7 \%$ of recipients) were willing to donate embryos for research.

Donors were less likely to believe that only recipients should be involved in giving consent for the use of EGDs in research ( $25.0 \%$ vs. $41.7 \%$ among recipients), and were more frequently favourable to the idea of exclusive donors' consent $(26.4 \%$ vs. $11.4 \%$ among recipients) (Table 1). Participants who were married or lived with the partner more often thought that consent should concern recipients alone compared to single or divorced participants.

Almost half of the donors (48.6\%) and half of the recipients $(46.9 \%)$ agreed with dual consent. This view was more frequent among employed recipients $(49.7 \%$ vs. $21.4 \%$ among recipients with other working status) (Table 2).

\section{Discussion}

This study revealed that almost half of the donors and half of the recipients considered that a dual consent procedure is desirable. However, recipients and donors had divergent views about who should be involved in the process of giving consent for the use of EGDs in research. These findings point to consent procedures becoming potentially disagreeable and distressing [21] and indicate the need to develop evidence-based and ethically sustainable policies and guidelines [15] to protect the well-being, autonomy and reproductive rights of both stakeholder groups $[8,22]$.

Donors may feel attached to embryos created with their gametes [23-25]. Such feelings of biological connectedness may entrench a sense of ownership over donated gametes [24, 26]. From a perspective of property rights, donors own all parts of their bodies and, therefore, should be awarded the authority to decide on the destiny of their gametes for both reproductive or research purposes [27]. Transferring more control 
Table 1 Opinion about involvement in consenting the use of EGDs in research, according to participants' characteristics

\begin{tabular}{|c|c|c|c|c|}
\hline & \multicolumn{4}{|c|}{ Who should be involved in giving consent to the use of EGDs in research } \\
\hline & $\overline{\text { Total }}$ & $\begin{array}{l}\text { Gamete } \\
\text { recipients }\end{array}$ & $\begin{array}{l}\text { Gamete } \\
\text { donors }\end{array}$ & $\begin{array}{l}\text { Both recipients and } \\
\text { gamete donors }\end{array}$ \\
\hline Overall, $n(\%)$ & 247 & $91(36.8)$ & $39(15.8)$ & $117(47.4)$ \\
\hline \multicolumn{5}{|l|}{ Experience with donation, $n(\%)$} \\
\hline Donors & 72 & $18(25.0)^{*}$ & $19(26.4)^{*}$ & $35(48.6)^{*}$ \\
\hline Recipients & 175 & $73(41.7)^{*}$ & $20(11.4)^{*}$ & $82(46.9)^{*}$ \\
\hline \multicolumn{5}{|l|}{ Sex, $n(\%)$} \\
\hline Female & 156 & $60(38.5)$ & $27(17.3)$ & $69(44.2)$ \\
\hline Male & 91 & $31(34.1)$ & $12(13.2)$ & $48(52.7)$ \\
\hline Age, Median (P25-P75) & 35.0 & $37.0(34.0-40.0)$ & $37.0(33.5-40.0)$ & $36.0(35.0-39.0)$ \\
\hline \multicolumn{5}{|l|}{ Educational level, $n$ (\%) } \\
\hline$\leq 12$ th grade & 130 & $48(36.9)$ & $21(16.2)$ & $61(46.9)$ \\
\hline$>12$ th grade & 113 & $40(35.4)$ & $18(15.9)$ & $55(48.7)$ \\
\hline \multicolumn{5}{|l|}{ Marital status, $n(\%)$} \\
\hline Married/Living with the partner & 172 & $71(41.3)^{*}$ & $21(12.2)^{*}$ & $80(46.5)^{*}$ \\
\hline Single/Divorced & 74 & $19(25.7)^{*}$ & $18(24.3)^{*}$ & $37(50.0)^{*}$ \\
\hline \multicolumn{5}{|l|}{ Working status, $n$ (\%) } \\
\hline Employed & 199 & $70(35.2)$ & $31(15.6)$ & $98(49.2)$ \\
\hline Other $^{a}$ & 45 & $19(42.2)$ & $8(17.8)$ & $18(40.0)$ \\
\hline \multicolumn{5}{|l|}{ Perceived income adequacy, $n$ (\%) } \\
\hline Insufficient & 72 & $31(43.0)$ & $12(16.7)$ & $29(40.3)$ \\
\hline Sufficient & 174 & $59(33.9)$ & $27(15.5)$ & $88(50.6)$ \\
\hline \multicolumn{5}{|l|}{ Parental status, $n(\%)$} \\
\hline No children & 215 & 79 (36.8) & $34(15.8)$ & $102(47.4)$ \\
\hline Children & 31 & $11(35.5)$ & $5(16.1)$ & $15(48.4)$ \\
\hline \multicolumn{5}{|c|}{ Previous experience on donation, $n$ (\%) } \\
\hline No & 185 & $66(35.7)$ & $32(17.3)$ & $87(47.0)$ \\
\hline Yes & 62 & $25(40.3)$ & $7(11.3)$ & $30(48.4)$ \\
\hline \multicolumn{5}{|l|}{ Embryo donation for research, $n(\%)$} \\
\hline Willing & 162 & 59 (36.4) & $27(16.7)$ & $76(46.9)$ \\
\hline Other ${ }^{\mathrm{b}}$ & 75 & $27(36.0)$ & $10(13.3)$ & $38(50.7)$ \\
\hline
\end{tabular}

NOTES: The total may not add up to 247 participants in each variable due to missing values

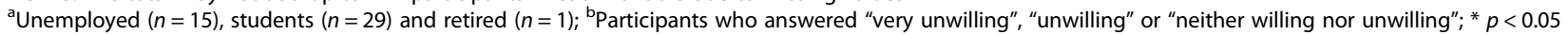

over decision-making about EGDs disposition to donors will allow policy-makers and regulators to demonstrate their appreciation for gamete donors, not least by respecting and accommodating their preferences [18].

Consent procedures for EGDs disposition that fail to involve one or more stakeholder groups risk leaving rightful parties feeling marginalised and mistrustful of gamete donation policies and guidelines. Taking donors' and recipients' views into consideration is thus crucial to develop people-centred policies and guidelines for consent on EGDs disposition that are mindful of all stakeholders' values and needs, and that aim to promote ever-evolving and trusted health systems [28-30].

The collection of data at a single reproductive centre is a limitation of this study. However, this is the only Public Bank of Gametes in Portugal, which allows for the generalizability of the opinions of both donors and recipients using the public healthcare system in the country where the study was undertaken. The findings of this study can be used as a baseline for subsequent qualitative studies aiming to provide a deeper understanding of the intricacies of negotiations on consent between gamete donors and recipients in cases where there is discordance. Nevertheless, there is a need for 
Table 2 Donors' and recipients' opinion about dual consent for using EGDs in research

\begin{tabular}{|c|c|c|c|c|c|c|}
\hline & \multicolumn{6}{|c|}{ Dual consent } \\
\hline & \multicolumn{3}{|c|}{ Donors } & \multicolumn{3}{|c|}{ Recipients } \\
\hline & $\begin{array}{l}\text { Total } \\
n=72\end{array}$ & $\begin{array}{l}\text { Disagree } \\
n=37\end{array}$ & $\begin{array}{l}\text { Agree } \\
n=35\end{array}$ & $\begin{array}{l}\text { Total } \\
n=175\end{array}$ & $\begin{array}{l}\text { Disagree } \\
n=93\end{array}$ & $\begin{array}{l}\text { Agree } \\
n=82\end{array}$ \\
\hline \multicolumn{7}{|l|}{ Sex, $n(\%)$} \\
\hline Female & 47 & $27(57.4)$ & $20(42.6)$ & 109 & $60(55.0)$ & $49(45.0)$ \\
\hline Male & 25 & $10(40.0)$ & $15(60.0)$ & 66 & $33(50.0)$ & $33(50.0)$ \\
\hline Age, Median (P25-P75) & 27.0 & $27.0(25.0-31.0)$ & $27.0(24.0-30.0)$ & 37.0 & $37.0(34.0-40.0)$ & $36.0(35.0-39.0)$ \\
\hline \multicolumn{7}{|l|}{ Educational level, $n(\%)$} \\
\hline$\leq 12$ th grade & 31 & $14(45.2)$ & $17(54.8)$ & 99 & $55(55.6)$ & $44(44.4)$ \\
\hline$>12$ th grade & 41 & $23(56.1)$ & $18(43.9)$ & 72 & 35 (48.6) & $37(51.4)$ \\
\hline \multicolumn{7}{|l|}{ Marital status, $n(\%)$} \\
\hline Married/Living with the partner & 13 & $7(53.8)$ & $6(46.2)$ & 159 & $85(53.5)$ & $74(46.5)$ \\
\hline Single/Divorced & 59 & $30(50.8)$ & $29(49.2)$ & 15 & $7(46.7)$ & $8(53.3)$ \\
\hline \multicolumn{7}{|l|}{ Working status, $n$ (\%) } \\
\hline Employed & 40 & $21(52.5)$ & $19(47.5)$ & 159 & $80(50.3)^{*}$ & $79(49.7)^{*}$ \\
\hline Other $^{\mathrm{a}}$ & 31 & $16(51.6)$ & $15(48.4)$ & 14 & $11(78.6)^{*}$ & $3(21.4)^{*}$ \\
\hline \multicolumn{7}{|l|}{ Perceived income adequacy, $n$ (\%) } \\
\hline Insufficient & 22 & $12(54.5)$ & $10(45.5)$ & 50 & $31(62.0)$ & $19(38.0)$ \\
\hline Sufficient & 50 & $25(50.0)$ & $25(50.0)$ & 124 & $61(49.2)$ & $63(50.8)$ \\
\hline \multicolumn{7}{|l|}{ Parental status, $n(\%)$} \\
\hline No children & 58 & $27(46.6)$ & $31(53.4)$ & 157 & $86(54.8)$ & $71(45.2)$ \\
\hline Children & 14 & $10(71.4)$ & $4(28.6)$ & 17 & $6(35.3)$ & $11(64.7)$ \\
\hline \multicolumn{7}{|c|}{ Previous experience on donation, $n$ (\%) } \\
\hline No & 66 & $35(53.0)$ & $31(47.0)$ & 119 & $63(52.9)$ & $56(47.1)$ \\
\hline Yes & 6 & $2(33.3)$ & $4(66.7)$ & 56 & $30(53.6)$ & $26(46.4)$ \\
\hline \multicolumn{7}{|l|}{ Embryo donation for research, $n(\%)$} \\
\hline Willing & 53 & $27(50.9)$ & $26(49.1)$ & 109 & $59(54.1)$ & $50(45.9)$ \\
\hline Other ${ }^{b}$ & 18 & $9(50.0)$ & $9(50.0)$ & 57 & $28(49.1)$ & $29(50.9)$ \\
\hline
\end{tabular}

NOTES: The total may not add up to 72 donors and 175 recipients in each variable due to missing values

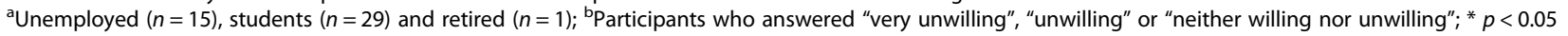

further quantitative and qualitative assessments of the views of donors and recipients on the use of EGDs in research in other countries and settings to enable comparison and inform the development of both local and global policy for an increasingly transnational practice as is the donation of gametes.

\section{Conclusions}

This study uncovers a need to promote an open discussion about ethically sustainable consent procedures in the field of gamete donation. It also stresses the importance of conducting more empirical research and further theoretical normative analyses [21] to inform people-centred policy and guidelines for shared decision-making concerning the use of EGDs for research.

\section{Supplementary information}

Supplementary information accompanies this paper at https://doi.org/10 1186/s12910-019-0430-6.

Additional file 1. "Gamete Donation: Public involvement and peoplecentred care Questionnaire". A translation of the questionnaire developed by the research team to assess ethical, legal and social issues involved in gamete donation.

Abbreviation

EGDs: Embryos created by gamete donation

\section{Acknowledgments}

The authors thank all the donors and recipients who participated in the study; the health professionals and the staff of the Portuguese Public Bank of Gametes who collaborated in participants' recruitment. Also, the authors would like to thank the research team of the ENGAgED project, for all the relevant comments and suggestions to this work. 


\section{Authors' contributions}

The study was designed by SS. IB and CdF wrote the first draft of the manuscript. SS, VP and IB designed the analysis strategy. CS and IB collected and analysed the data. All authors gave a substantial contribution to the interpretation of data, critical discussion and revision of the manuscript, and approved its final version.

\section{Funding}

This study was co-funded by national funding from the Foundation for Science and Technology - FCT (Portuguese Ministry of Science, Technology and Higher Education), the Operational Programmes Competitiveness and Internationalization (COMPETE 2020) and Human Capital (POCH), Portugal 2020, and the European Union, through the European Regional Development Fund and the European Social Fund, under the projects "Bionetworking and citizENship on GAmetE Donation (ENGAgED)" (POCI-01-0145-FEDER-016762; Ref. FCT PTDC/IVC-ESCT/6294/2014) and "Public and patient involvement in health data governance: a people-centred approach to data protection in genetic diseases (DATAGov)" (POCI-01-0145-FEDER-032194; AAC n 02/SAICT/2017), the Unidade de Investigação em Epidemiologia - Instituto de Saúde Pública da Universidade do Porto (EPIUnit) (POCI-01-0145-FEDER-006862; Ref. FCT UID/DTP/04750/2013), the PhD grant SFRH/BD/111686/2015 (IB), the DL57/2016/CP1336/CT0001 (CF) and the FCT Investigator contract IF/01674/2015 (SS). The funding body had no role in the design of the study and collection, analysis, and interpretation of data and in writing the manuscript.

\section{Availability of data and materials}

The datasets generated and analysed during the current study are not publicly available due to a confidentiality agreement securing participants' privacy and anonymity but are available from the corresponding author on reasonable request.

\section{Ethics approval and consent to participate}

Ethics approval was granted by the Portuguese Data Protection Authority and the Ethics Committee for Health from the Centro Hospitalar Universitário do Porto, where data was collected, and all procedures performed in this study involving human participants were in accordance with the ethical standards of 1964 Helsinki declaration and its later amendments. Written informed consent was obtained from all donors and recipients prior to participation in the study, following the World Medical Association Declaration of Helsinki and the Oviedo Convention.

\section{Consent for publication}

Written informed consent for publication of data was obtained from all individual participants included in the study.

\section{Competing interests}

The authors declare that they have no competing interests.

\section{Author details}

'EPIUnit - Instituto de Saúde Pública, Universidade do Porto, Rua das Taipas, no 135, 4050-600 Porto, Portugal. ${ }^{2}$ Departamento de Ciências da Saúde Pública e Forenses e Educação Médica, Faculdade de Medicina, Universidade do Porto, Porto, Portugal. ${ }^{3}$ Centre for Research and Studies in Sociology, University Institute of Lisbon (ISCTE-IUL), Lisbon, Portugal. ${ }^{4}$ Bioethics Institute Ghent, Department of Philosophy and Moral Sciences Ghent University, Ghent, Belgium.

Received: 19 February 2019 Accepted: 21 November 2019 Published online: 02 December 2019

\section{References}

1. European Society of Human Reproduction and Embryology (ESHRE) Task Force on Ethics and Law. II. The cryopreservation of human embryos. Hum Reprod. 2001;16(5):1049-50

2. Lo B, Parham L, Cedars M, Fisher S, Gates E, Giudice L, et al. Research ethics. $\mathrm{NIH}$ guidelines for stem cell research and gamete donors. Science. 2010; 327(5968):962-3.

3. de Portugal G. Lei n. $32 / 2006$ de 26 de julho. Procriação Medicamente Assistida. Portugal: Diário da República, 1a Série - №143; 2006. p. 5245-50.

4. The Ethics Committee of American Society for Reproductive Medicine (ASRM). Informed consent and the use of gametes and embryos for research: a committee opinion. Fertil Steril. 2014;101(2):332-5.
5. Nelson E, Mykitiuk R, Nisker J. Informed consent to donate embryos for research purposes. J Obstet Gynaecol Can. 2008;30(9):824-9.

6. Caulfield T, Murdoch B. Genes, cells, and biobanks: yes, there's still a consent problem. PLoS Biol. 2017;15(7):e2002654.

7. Archard D. Informed consent: autonomy and self-ownership. J Appl Philos. 2008;25(1):19-34.

8. Buyx A, Del Savio L, Prainsack B, Volzke H. Every participant is a PI. Citizen science and participatory governance in population studies. Int J Epidemiol. 2017:46(2):377-84.

9. Björkman B, Hansson SO. Bodily rights and property rights. J Med Ethics. 2006;32(4):209-14.

10. Pennings $\mathrm{G}$. The validity of contracts to dispose of frozen embryos. J Med Ethics. 2002;28(5):295-8.

11. Kaye J, Whitley EA, Lund D, Morrison M, Teare H, Melham K. Dynamic consent: a patient interface for twenty-first century research networks. Eur J Hum Genet. 2015;23(2):141-6.

12. Klitzman R. Unconventional combinations of prospective parents: ethical challenges faced by IVF providers. BMC Med Ethics. 2017;18(1):18.

13. Lo B, Chou V, Cedars Ml, Gates E, Taylor RN, Wagner RM, et al. Medicine. Consent from donors for embryo and stem cell research. Science. 2003;301(5635):921.

14. Pennings G, Ravel C, Girard JM, Domin-Bernhard M, Provoost V. Attitude towards reciprocity as a motive for oocyte donation. Eur J Obstet Gynecol Reprod Biol. 2018;225:194-8.

15. Stroud K, O'Doherty KC. Ethically sustainable governance in the biobanking of eggs and embryos for research. Monash Bioeth Rev. 2015;33(4):277-94.

16. Nuffield Council on Bioethics. Public Health: ethical issues. London: Nuffield Council on Boethics; 2007.

17. Førde R. How can empirical ethics improve medical practice? Camb Q Healthc Ethics. 2012;21(4):517-26.

18. Schaefer GO, Sinaii N, Grady C. Informing egg donors of the potential for embryonic research: a survey of consent forms from US IVF clinics. Fertil Steril. 2012;97(2):427-33.

19. International Federation of Fertility Societies (IFFS). IFFS surveillance 2019: global trends in reproductive policy and practice, 8th edition. Glob Reprod Health. 2019:1(e1):1-143.

20. Costa R. PMA: "É quase inevitável que as listas de espera aumentem". TSF Online. 2017; http://www.tsf.pt/sociedade/saude/interior/pma-equaseinevitavel-que-as-listas-de-espera. Accessed 5 Aug 2019.

21. Ives J, Dunn M, Molewijk B, Schildmann J, Baeroe K, Frith L, et al. Standards of practice in empirical bioethics research: towards a consensus. BMC Med Ethics. 2018;19(1):68.

22. Waldby C, Kerridge I, Boulos M, Carroll K. From altruism to monetisation: Australian women's ideas about money, ethics and research eggs. Soc Sci Med. 2013:94:34-42.

23. Baylis F, Widdows H. Human embryos and eggs: from long-term storage to biobanking. Monash Bioeth Rev. 2015;33(4):340-59.

24. Franklin S. From blood to genes?: rethinking Cosanguinity in the context of Geneticization. In: Johnson CH, Jussen B, Sabean DW, Teuscher S, editors. Blood and kinship: matter for metaphor from ancient Rome to the present. Berghahn: New York and Oxford; 2013. p. 285-320.

25. Samorinha C, Severo M, Machado H, Figueiredo B, De Freitas C, Silva S. Couples' willingness to donate embryos for research: a longitudinal study. Acta Obstet Gynecol Scand. 2016;95(8):912-9.

26. Kirkman M, Bourne K, Fisher J, Johnson L, Hammarberg K. Gamete donors' expectations and experiences of contact with their donor offspring. Hum Reprod. 2014;29(4):731-8.

27. Zeiler K. Neither property right nor heroic gift, neither sacrifice nor aporia: the benefit of the theoretical lens of sharing in donation ethics. Med Health Care Philos. 2014:17(2):171-81.

28. World Health Organisation (WHO). Framework on Integrated PeopleCentred Health Services Geneva: WHO Framework on IPCHS platform. http://www.who.int/servicedeliverysafety/areas/people-centred-care/en/ (2016). Accessed 17 Dec 2018.

29. Cascio MA, Racine E. Person-oriented research ethics: integrating relational and everyday ethics in research. Account Res. 2018;25(3):170-97.

30. Samorinha C, Silva S. A patient-centred approach to embryo donation for research. Isr J Health Policy Res. 2016;5:44.

\section{Publisher's Note}

Springer Nature remains neutral with regard to jurisdictional claims in published maps and institutional affiliations. 